\title{
Investigation on Material Deformation Characteristics of Ultrasound-assisted Microcompression with Dynamic Force Sensing Technology
}

\author{
Jun $\mathrm{Hu}^{*}{ }^{*}$ Tetsuhide Shimizu, and Ming Yang \\ Graduate School of System Design, Tokyo Metropolitan University, \\ 6-6 Asahigaoka, Hino, Tokyo 191-0065, Japan
}

(Received March 5, 2019; accepted May 24, 2019)

Keywords: ultrasonic vibration, volume effect, stress superposition, acoustic softening, copper, microforming

Ultrasonic vibration is a promising assistant technology to improve the microforming processes, for example, decreasing friction, enhancing surface finishing, and reducing forming load/stress. However, the mechanism behind the forming stress reduction due to ultrasonic vibration, so-called acoustic softening, is still not totally understood, because in most previous research studies, a simplified force sensing technology, which could not measure the real dynamic ultrasonic force during deformation, was used. In order to solve this issue, an ultrasound-assisted microcompression test system with a die-embedded dynamic force sensor was developed for studying the evolution of acoustic softening. With this system, the stress reduction by acoustic softening can be obtained by separating the stress reduction by stress superposition, which is just an apparent stress reduction due to the averaging of the dynamic oscillatory stress. Then, the stress reduction by stress superposition is verified using a theoretical model, confirming the reliability of the test system. Thus, the evolution of material deformation characteristics can be analyzed. By comparing the stress superposition to acoustic softening, it is found that stress superposition is greater than acoustic softening at the beginning of deformation, especially with a smaller ultrasonic amplitude. Even as the ratio of stress superposition to acoustic softening gradually decreases to some extent with increasing strain, stress superposition still accounts for nearly half of the total stress reduction. The results emphasize the importance of the dynamic force sensing technology in ultrasound-assisted microforming and provide some instructive understanding of the mechanism of acoustic softening.

\section{Introduction}

From the last decade, the application of ultrasonic assistance has been attracting increasing attention in microforming. ${ }^{(1-8)}$ The benefits of ultrasonic vibration in microforming mainly include the surface and volume effects. The surface effect can lower the interfacial friction

*Corresponding author: e-mail: johnnyhu1992@gmail.com https://doi.org/10.18494/SAM.2019.2359 
force between vibrated tools and specimens, ${ }^{(9)}$ resulting in a better surface finishing, ${ }^{(10)}$ and has been well studied in the past. The volume effect causes a reduction in forming stress during processing, ${ }^{(11)}$ but the mechanism of which has not been thoroughly understood. Some researchers proposed that the volume effect is due to the easier dislocation fusion when ultrasonic energy is applied, ${ }^{(12)}$ which is commonly called acoustic softening. Some others insist that the volume effect is just an apparent stress reduction due to the averaging of the dynamic oscillatory stress, ${ }^{(13)}$ which is called stress superposition without the change of materials during processing. These two theories have been debated for decades but no conclusions can be drawn, hence which theory is true or whether both occur under certain condition is still unclear.

Some researchers ${ }^{(14-16)}$ tried to study the volume effect using the compression or tension test; however, owing to the simplification of the force sensing technology, the real dynamic oscillatory forming forces could not be measured and the average stress of the dynamic oscillatory forming stress was used as the real forming stress in analysis. This misoperation may overestimate the real stress reduction by acoustic softening, since the stress reduction by stress superposition is not taken into consideration. Thus, in order to obtain the real stress reduction of the material owing to acoustic softening, the dynamic oscillatory stress/force during the deformation with ultrasonic assistance should be measured.

The objective of this study is to apply the sensing technology of dynamic force measurement to ultrasound-assisted microforming. Thus, an ultrasound-assisted microcompression test system capable of measuring the dynamic oscillatory forces was developed, and the reliability of the system was confirmed. With this system, the stress reduction by stress superposition can be obtained. Then, the real stress reduction of the material by acoustic softening can be inferred to analyze the evolution of material deformation characteristics.

\section{Experimental Procedure}

The configuration of the ultrasound-assisted microcompression test system is shown in Fig. 1. The compression test is carried out in a desktop miniature servo press machine, designed by Micro Manufacturing LLC, as shown in Fig. 1(a). The minimum and maximum motion speeds of the crosshead in the press machine are 0.001 and $300 \mathrm{~mm} / \mathrm{s}$, respectively, and the step accuracy of $1 \mu \mathrm{m}$ guarantees the precise positioning of the crosshead in experiments. Besides the press machine, the test system also includes a die tool assembly, an ultrasonic vibrator, and a data collection module, as shown in Fig. 1(b).

The vibrator generates ultrasonic vibration on the punch, and the schematic of the vibrator is shown in Fig. 2. The ultrasonic vibration originates from the two piezo transducers with a frequency of $60 \mathrm{kHz}$ on the left and right sides of the vibrator. With the amplification of the specially designed horizontal and cross-shaped horns, the ultrasonic vibration is amplified and transformed in the vertical direction. Eventually, with further amplification by the punch, the maximum amplitude on the punch tip could be $3.21 \mu \mathrm{m}$, measured using a laser doppler vibrometer (Nihon Kagaku Eng.; resolution: $0.01 \mu \mathrm{m}$, sampling frequency: $1 \mathrm{MkHz}$, and velocity: $0.1-1000 \mathrm{~mm} / \mathrm{s} / \mathrm{V})$. The vibrator is fixed inside the die tool assembly, which is mounted to the crosshead of the press machine, so the motion of the punch follows that of the crosshead precisely. 


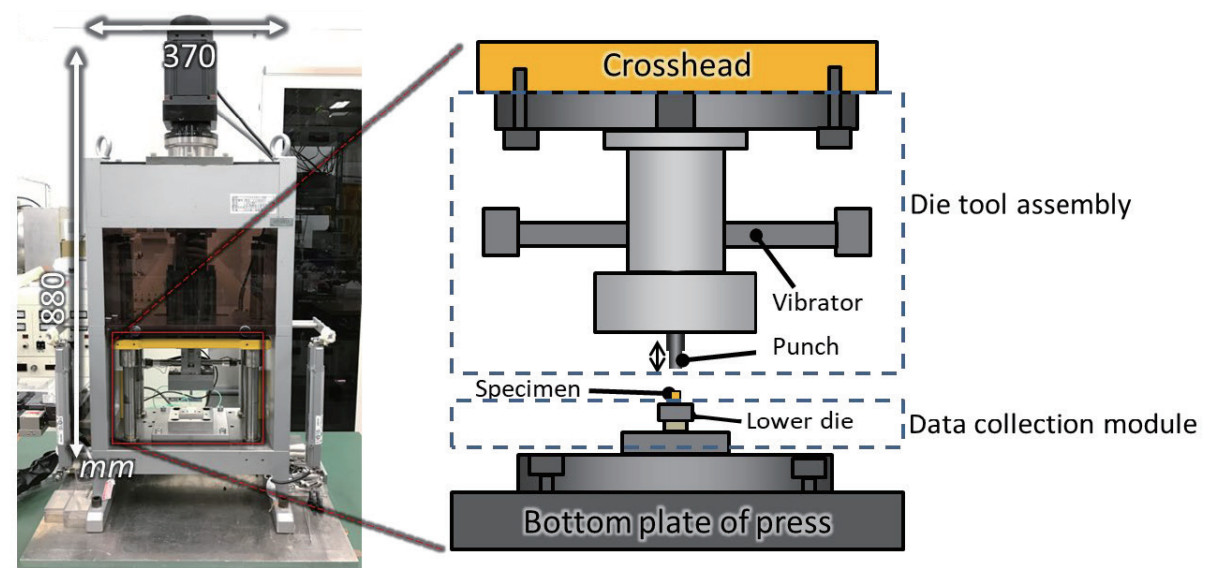

(a)

(b)

Fig. 1. (Color online) Configuration of the ultrasound-assisted microcompression test system. (a) Appearance of desktop miniature servo press machine. (b) Schematic illustration of microcompression test system.

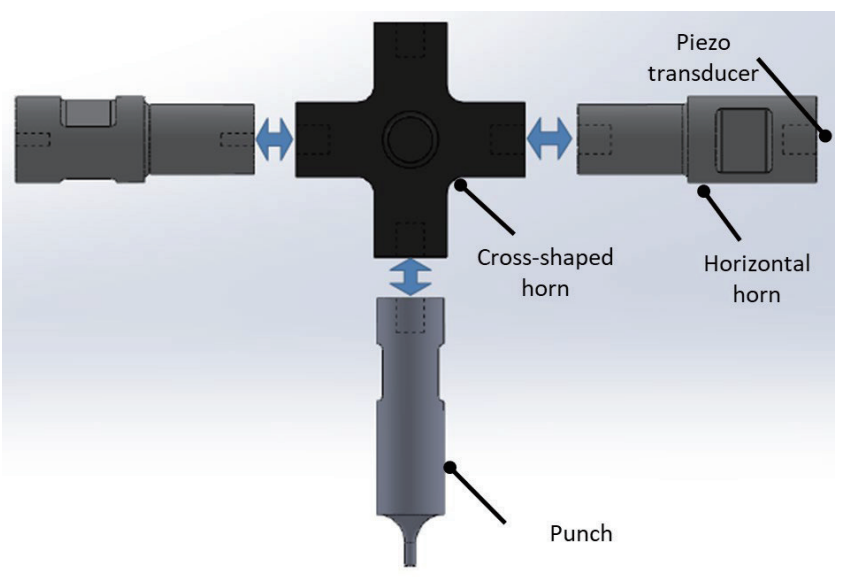

Fig. 2. (Color online) Schematic illustration of the vibrator.

A schematic illustration of the data collection module is shown in Fig. 3. To accurately record the dynamic forces with a high frequency of $60 \mathrm{kHz}$, a quartz load cell [Kistler 9132B; measuring range: $0-7 \mathrm{kN}$, sensitivity: $-3.8 \mathrm{pC} / \mathrm{N}$, rigidity: $1.8 \mathrm{kN} / \mu \mathrm{m}$, and linearity (preloaded): $1.0 \% / \mathrm{FSO}$ ] with a high resolution, a high rigidity, and extremely small dimensions is used in this study. Because of the high rigidity of the sensor, it is especially suitable for measuring rapidly changing forces. To maintain the rigidity of the data collection module, the load cell is mounted between the lower die and a tightening plate secured with a tightening bolt, with a preload of about $1.5 \mathrm{kN}$. As a result, the measuring range of the forces in the system is 0 to $6 \mathrm{kN}$. The dynamic load cell is first connected to a signal amplifier (Kistler, 5011), then 


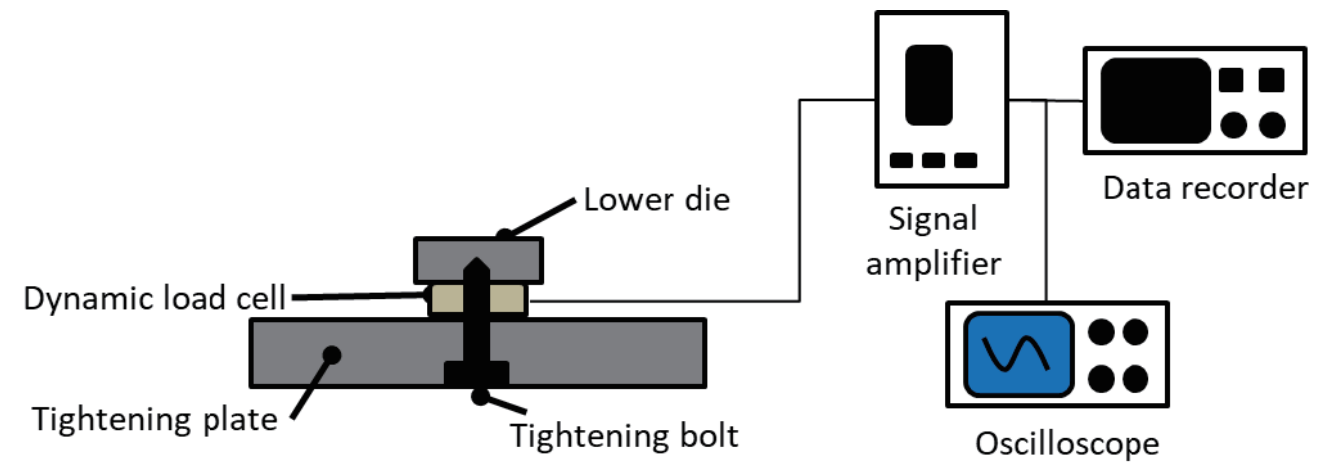

Fig. 3. (Color online) Schematic illustration of data collection module.

connected to a data recorder (OMRON ZR-RX70) and an oscilloscope (Tektronix, DPO2014) separately. During the experiments, the average force is measured by the data recorder, and the dynamic force is recorded via the oscilloscope with a bandwidth of $100 \mathrm{MHz}$ and a sampling rate of $1 \mathrm{GS} / \mathrm{s}$.

In this study, pure copper (C1100-O) cut from wires with a diameter of $2 \mathrm{~mm}$ is chosen as the experimental specimen with a size of $\varnothing 2 \times 2 \mathrm{~mm}^{2}$. At the beginning of the experiment, the cylinder specimen is placed at the center of the lower die. Then, the punch is gradually moved down until it comes into contact with the specimen, which should be indicated by a force change in the data recorder. After that, the ram of the press machine starts to move down with the displacement of half the height of the specimen. In order to maintain the stability of the specimen, the ultrasonic vibration is turned on until the displacement of $0.1 \mathrm{~mm}$. During the experiment, the average force of the load cell is continuously measured by the data recorder, and the dynamic force is discretely recorded by the oscilloscope after each $0.1 \mathrm{~mm}$ of displacement. Eventually, the forces and dynamic forces are combined, and the evolution of the real compression forces can be obtained. Three different ultrasonic amplitudes of 1.00, 2.00, and $3.21 \mu \mathrm{m}$ are applied in this study.

\section{Results and Discussion}

\subsection{Stress-strain curves with dynamic oscillatory stress}

In order to verify the reliability of the sensing system in this study, waveforms of the dynamic oscillatory forces are recorded during the experiments; one typical waveform is shown in Fig. 4. The waveform is an ideal sine wave, which is the same as the input electrical signal to the piezo transducer. This confirms that the sensing system can record the ultrasonic force signal.

Force is converted to stress, and the stress-strain relationship is presented in Fig. 5. The solid lines represent the original stress without ultrasonic vibration and the average stress of the dynamic stress with ultrasonic vibration at different amplitudes. The dashed lines represent the 


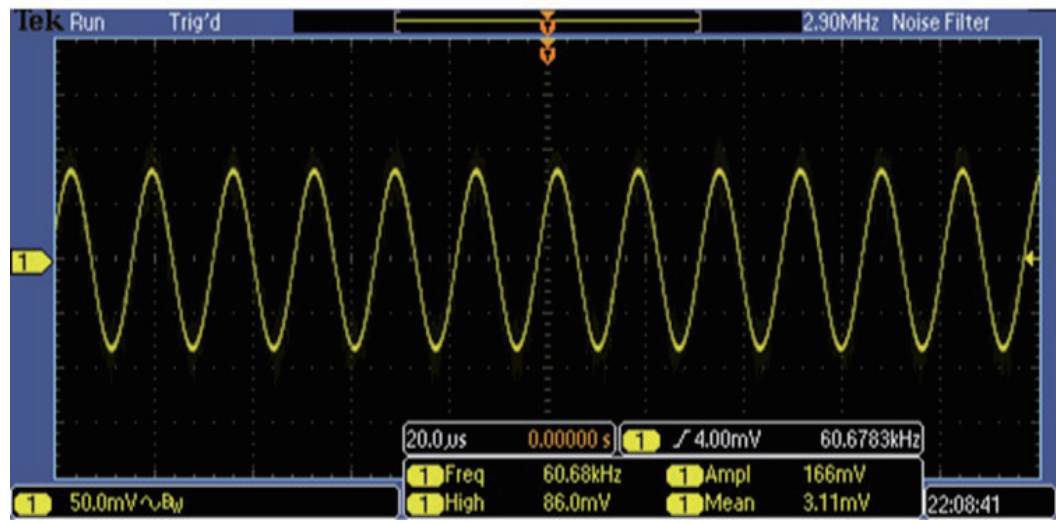

Fig. 4. (Color online) Typical waveform of dynamic oscillatory forces during compression with different ultrasonic amplitudes.

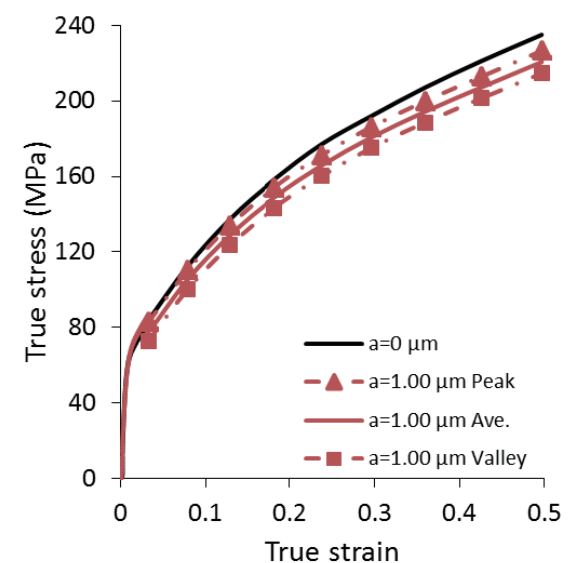

(a)

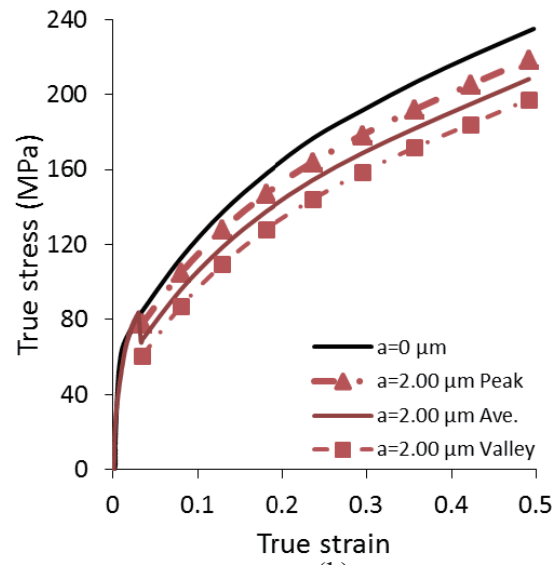

(b)

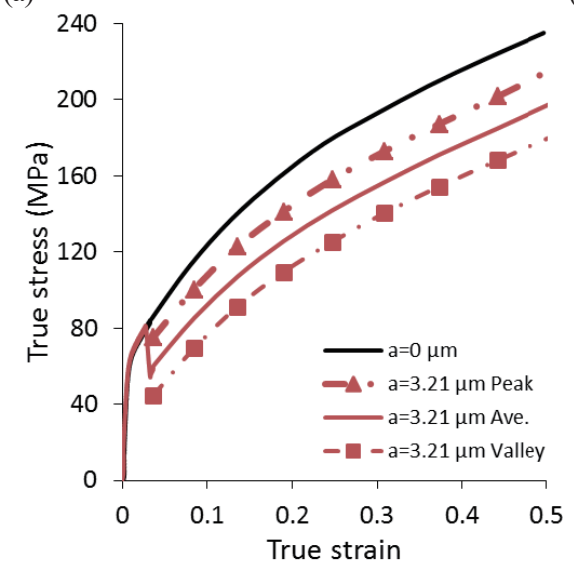

(c)

Fig. 5. (Color online) True stress-strain curves of ultrasound-assisted compression tests considering oscillatory stress with various amplitudes of (a) 1.00 , (b) 2.00 , and (c) $3.21 \mu \mathrm{m}$.

maximum and minimum stresses of the dynamic stress, which are the peak and valley values in Fig. 5. It can be seen that once the ultrasonic vibration is applied, a significant stress reduction occurs and the reduction increases with amplitude. 
By subtracting the average dynamic stress from the original stress without ultrasonic vibration, the total stress reduction can be obtained. Its evolution is shown in Fig. 6. However, note that the total stress reduction is not the actual stress reduction related to the changes in the material properties owing to acoustic softening. To obtain the real stress reduction, the stress superposition owing to the dynamic oscillatory stress should be separated.

\subsection{Verification of stress superposition by the dynamic stress}

According to its definition, stress superposition could be obtained by subtracting the average value from the peak value of the dynamic oscillatory stress. The evolution of stress superposition is shown in Fig. 7.

To verify the reliability of the measured value of stress superposition, a model ${ }^{(17)}$ is used and the results are compared with the experimental result. In this hybrid model of stress superposition, the deformation of the compression system is taken into consideration to better predict the exact value of stress superposition. In this way, the theoretical value of stress superposition can be compared with the experimental value. The results are shown in Fig. 8. The theoretical value fits well with the experimental value, indicating the reliability of the measurement of dynamic forces in this study.

\subsection{Evolution of real stress reduction}

Since the total stress reduction is the sum of stress superposition and acoustic softening, the exact value of acoustic softening can be obtained by subtracting the stress superposition from the total stress reduction, as shown in Fig. 9(a). It can be seen that the real stress reduction increases with amplitude. This is because with a higher ultrasonic amplitude, the ultrasonic energy absorbed by a material for plastic deformation also increases; thus, the flowing stress needed is further reduced, resulting in the increase in real stress reduction. To compare stress superposition and acoustic softening, the ratio of these two components of stress reduction

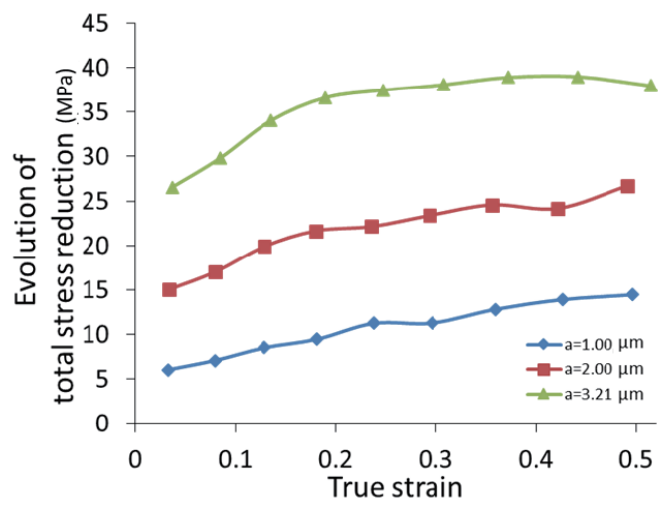

Fig. 6. (Color online) Evolution of total stress reduction.

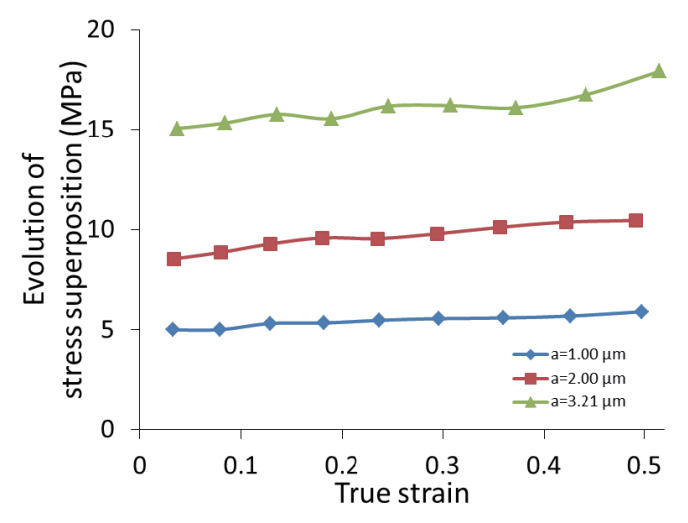

Fig. 7. (Color online) Evolution of stress reduction by stress superposition. 


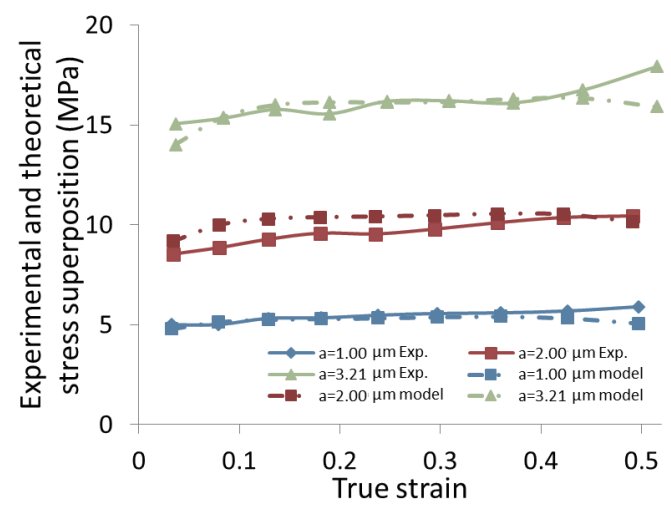

Fig. 8. (Color online) Model-based calculation and experimental results of stress superposition.

(a)
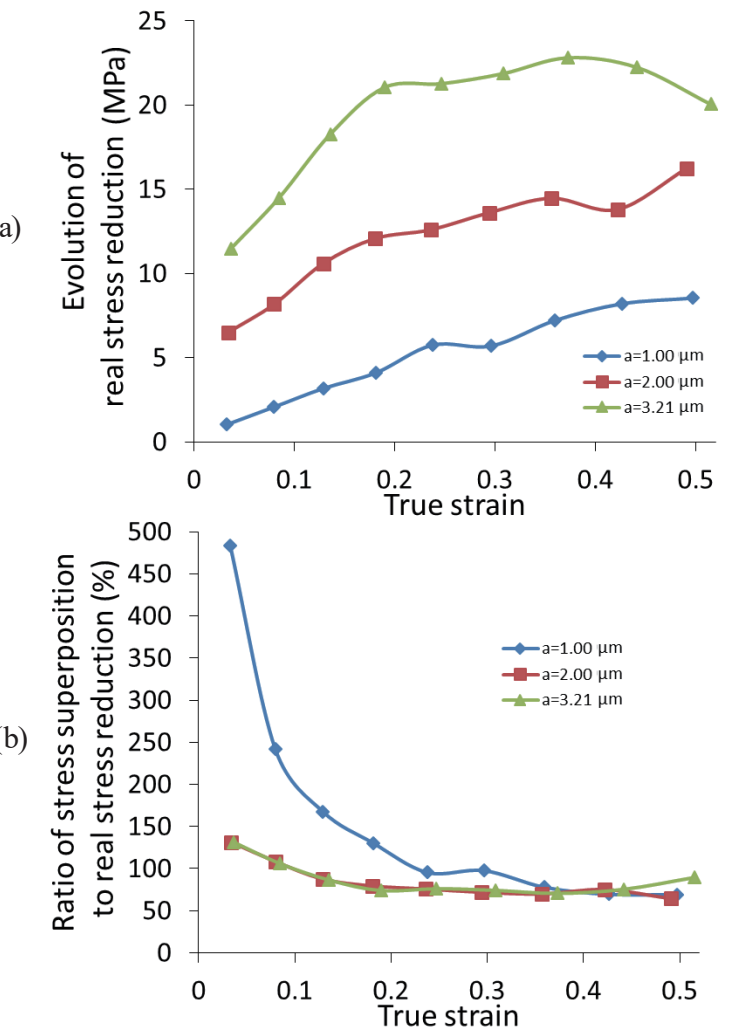

Fig. 9. (Color online) Evolution of real stress reduction by acoustic softening and stress superposition.

is calculated and presented in Fig. 9(b). It can be seen that stress superposition is larger than acoustic softening at the beginning of the strain. Particularly with the amplitude of $1.00 \mu \mathrm{m}$, stress superposition is almost 5 times as large as acoustic softening. Thus, the amount of stress superposition in the total stress reduction is quite large at the beginning of deformation and should not be ignored as it was in most previous studies. As the strain increases, the ratio gradually decreases, and after the strain of about 0.3 , the ratio starts to saturate at about $80 \%$. 
Hence, the component of stress superposition still accounts for nearly half the total stress reduction. This evolution of the ratio of stress superposition to acoustic softening exemplifies the importance of separating different components of stress reduction by ultrasonic vibration.

\section{Conclusions}

In this study, an ultrasonic-assisted microcompression test system was developed for studying the evolution of acoustic softening. To obtain the stress reduction by acoustic softening, dynamic oscillatory forces were measured with a die-embedded quartz sensor. With this system, the stress reduction by stress superposition can be determined. The stress reduction by stress superposition was verified with the theoretical model, and the reliability of the system was confirmed. Then, the real stress reduction of the material by acoustic softening was inferred to analyze the evolution of material deformation characteristics. By comparing stress superposition to acoustic softening, we found that stress superposition was larger than acoustic softening at the beginning of deformation, especially with a smaller ultrasonic amplitude. Even as the ratio of stress superposition to acoustic softening gradually decreased to some extent with increasing strain, stress superposition still accounted for nearly half the total stress reduction, which emphasized the importance of separating stress superposition from acoustic softening by dynamic force sensing technology.

\section{Acknowledgments}

The authors would like to express their gratitude to Professor Masahiko Jin (Nippon Institute of Technology) for designing the ultrasonic vibrator. The authors would also like to express their gratitude to Mr. Yohei Suzuki (Komatsuseiki Kosakusho. Co., Ltd.) for designing the compression die.

\section{References}

1 Y. Bai and M. Yang: Int. J. Precis. Eng. Manuf. 16 (2015) 685. https://doi.org/10.1007/s12541-015-0091-4

2 J. Hu, T. Shimizu, and M. Yang: Mater. Sci. Forum 920 (2018) 102. https://doi.org/10.4028/www.scientific.net/ MSF.920.102

3 J. Hu, T. Shimizu, and M. Yang: Procedia Eng. 207 (2017) 1063. https://doi.org/10.1016/j.proeng.2017.10.1131.

4 K. Mita, J. Hu, T. Shimizu, and M. Yang: Procedia Manuf. 15 (2018) 627. https://doi.org/10.1016/ J.PROMFG.2018.07.287

5 W. Presz: AIP Conf. Proc. 1960 (2018) 100012.

6 T. Shimizu, S. Kosuge, and M. Yang: Manuf. Rev. 2 (2015) 5. https://doi.org/10.1051/mfreview/2015006

7 R. Yamaguchi, Y. Bai, T. Sshimizu, and M. Yang: Mech. Eng. J. 14 (2015) 410. https://doi.org/10.1299/mej.1400410

8 Z. Yao, G. Y. Kim, L. Faidley, Q. Zou, D. Mei, and Z. Chen: J. Mater. Process. Technol. 212 (2012) 640. https:// doi.org/10.1016/j.jmatprotec.2011.10.017

9 H. Storck, W. Littmann, J. Wallaschek, and M. Mracek: Ultrasonics 40 (2002) 379. https://doi.org/10.1016/ S0041-624X(02)00126-9

10 Y. Bai and M. Yang: J. Mater. Process. Technol. 229 (2016) 367. https://doi.org/10.1016/j.jmatprotec.2015.06.006

11 J. Hu, T. Shimizu, T. Yoshino, T. Shiratori, and M. Yang: J. Mater. Process. Technol. 258 (2018) 144. https:// doi.org/10.1016/j.jmatprotec.2018.03.021

12 B. Langenecker: IEEE Trans. Sonics Ultrason. 13 (1966) 1. https://doi.org/10.1109/T-SU.1966.29367 
13 H. O. K. Kirchner, W. K. Kromp, F. B. Prinz, and P. Trimmel: Mater. Sci. Eng. 68 (1985) 197. https://doi. org/10.1016/0025-5416(85)90409-4

14 V. Fartashvand, A. Abdullah, and S. A. Sadough Vanini: Ultrason. Sonochem 38 (2017) 744. https://doi. org/10.1016/j.ultsonch.2016.07.007

15 H. Zhou, H. Cui, Q. H. Qin, H. Wang, and Y. Shen: Mater. Sci. Eng. A. 682 (2017) 376. https://doi.org/10.1016/ j.msea.2016.11.021

16 S. Jiang, Y. Jia, H. Zhang, Z. Du, Z. Lu, K. Zhang, Y. He, and R. Wang: J. Mater. Eng. Perform. 26 (2017) 1769. https://doi.org/10.1007/s11665-017-2598-6

17 J. Hu, T. Shimizu, and M. Yang: Ultrason. Sonochem. 48 (2018) 240. https://doi.org/10.1016/ j.ultsonch.2018.05.039 